\title{
Analysis of $\left(\mathrm{NH}_{4}\right)_{6} \mathrm{Mo}_{7} \mathrm{O}_{24} \cdot 4 \mathrm{H}_{2} \mathrm{O}$ thermal decomposition in argon
}

\author{
A. Biedunkiewicz • M. Krawczyk • \\ U. Gabriel-Polrolniczak $\cdot$ P. Figiel
}

Received: 11 June 2013/Accepted: 2 December 2013/Published online: 22 December 2013

(C) The Author(s) 2013. This article is published with open access at Springerlink.com

\begin{abstract}
Nanometric carbides of transition metals and silicon are obtained by using precursors. Control of the course of these processes require data concerning transformations of single precursor, transformations of precursor in the presence of reducing agent and synthesis of the carbide. In this work, the way of investigating such processes is described on the example of thermal decomposition of $\left(\mathrm{NH}_{4}\right)_{6} \mathrm{Mo}_{7} \mathrm{O}_{24} \cdot 4 \mathrm{H}_{2} \mathrm{O}$ (precursor) in argon. The measurements were carried out by TG-DSC method. The solid products were identified by XRD method, and the gaseous products were determined by mass spectrometry method. There was demonstrated that the investigated process proceeded in five stages. Kinetic models (forms of $f(\alpha)$ and $g(\alpha)$ function) most consistent with experimental data and coefficients of Arrhenius equation $A$ and $E$ were determined for the stages. The Kissinger method and the Coats-Redfern equation were applied. In case of the Coats-Redfern equation, the calculations were performed by analogue method. In this way good consistency between the calculated and determined conversion degrees $\alpha(T)$ at practically constant values of $A$ and $E$ were obtained for distinguished stages and different sample heating rates.
\end{abstract}

Keywords Decomposition of $\left(\mathrm{NH}_{4}\right)_{6} \mathrm{Mo}_{7} \mathrm{O}_{24} \cdot 4 \mathrm{H}_{2} \mathrm{O}$ in argon - Thermal analysis - Process kinetics - Kissinger method $\cdot$ Coats-Redfern equation

A. Biedunkiewicz $\cdot$ M. Krawczyk $(\square) \cdot$ P. Figiel

Institute of Materials Science and Engineering, West

Pomeranian University of Technology, Piastow Av. 19,

Szczecin, Poland

e-mail: mkrawczyk@zut.edu.pl

U. Gabriel-Polrolniczak

Department of Physics and Chemistry, Maritime University of

Szczecin, Waly Chrobrego 1-2, Szczecin, Poland

\section{Abbreviations}

$A$ $B$

$C$

E Apparent activation energy/ $/ \mathrm{mol}^{-1}$,

$f(\alpha) \quad$ Conversion function dependent on mechanism of reaction

$f^{\prime}\left(\alpha_{\mathrm{m}}\right) \quad$ Derivative of $f(\alpha)$ function for maximal reaction rate

$\varphi(T, \alpha, P) \quad$ Temperature, conversion degree and pressure function

$g(\alpha) \quad$ Integral form of kinetic model

$h(P) \quad$ Pressure function

$k(T) \quad$ Reaction rate constant/ $1 \mathrm{~min}^{-1}$

$m_{0} \quad$ Initial sample mass for the stage $/ \mathrm{mg}$

$m \quad$ Current sample mass for the stage/mg

$m_{\mathrm{k}} \quad$ Final sample mass after for the stage/mg

$r \quad$ Reaction rate/ $1 \mathrm{~min}^{-1}$

$R \quad$ Gas constant $/ \mathrm{J} \mathrm{mol}^{-1} \mathrm{~K}$

$r_{\mathrm{p}} \quad$ Correlation coefficient

$t \quad$ Time/min

$T \quad$ Temperature/K

$T_{\alpha=0}, T_{\alpha=1} \quad$ Initial and final temperature of the stage/K

$T_{\mathrm{m}} \quad$ Maximum conversion rate temperature for a stage/K

$\Delta T \quad$ Temperature range/ $\mathrm{K}$

$\mathrm{TG}_{\mathrm{u}} \quad$ Normalised TG

$\alpha \quad$ Conversion degree

$\alpha_{\mathrm{m}} \quad$ Conversion degree for a stage maximum

$\Delta \alpha \quad$ Conversion degree range

$\beta \quad$ Heating rate/ $\mathrm{K} \min ^{-1}$

\section{Subscripts}

m Maximum 
$\alpha \quad$ Conversion degree

$i, j \quad$ Order

\section{Foreword}

The research in our laboratory focuses on manufacturing and application of nanometric carbides of transition metals and silicon [1-4]. Various precursors and reducing agents are used. The synthesis of the carbides is carried out under inert atmosphere of argon. Application of precursors in combination with sol-gel method enables easy controlling of mixture compositions and obtaining products of nanometric particles size [2-5]. There should be added that the same precursor can be used in different processes (e.g. obtaining single carbides, composites and application of different reducing agents). The studies carried out on the synthesis of carbides demonstrate that during the control of the course of the processes data concerning transformations of single precursors, transformations of precursor in the presence of reducing agent and synthesis of the carbides are of great importance [2, 3]. Ceramics containing molybdenum are important for applicational reasons $[2,6$, 7]. Their synthesis with application of nanometric $\mathrm{MoO}_{3}$ obtained from $\left(\mathrm{NH}_{4}\right)_{6} \mathrm{Mo}_{7} \mathrm{O}_{24} \cdot 4 \mathrm{H}_{2} \mathrm{O}$ (precursor) have been described in works [2, 3]. In this work, the method of investigating such processes and the way of analysing measurements results are presented on the example of thermal decomposition of $\left(\mathrm{NH}_{4}\right)_{6} \mathrm{Mo}_{7} \mathrm{O}_{24} \cdot 4 \mathrm{H}_{2} \mathrm{O}$ (precursor) in argon. The course of the process was studied by TG-DSC method under non-isothermal processes. The solid products were identified by XRD method, and the gaseous products were determined by mass spectrometry method. The result of measurements are analysed by methods of non-catalytic heterogeneous processes kinetics.

\section{Introduction}

In theory of kinetics of non-catalytic heterogeneous reactions, it is assumed that the reaction rate depends on temperature and conversion degree [1-5]

$r=\frac{\mathrm{d} \alpha}{\mathrm{d} t}=\phi(T, \alpha)$.

Under conditions of thermogravimetric measurements, the influence of pressure is negligible [8]. In traditional terms the domain of $\varphi(T, \alpha)$ function is an open area of the plane $(T, \alpha)$. The $\varphi(T, \alpha)$ function should be smooth. If this way is not sufficiently accurate, one can try to use the nonplanar surfaces. Such surfaces are called manifolds [9]. For the considered processes two-manifold $\mathrm{S}$ can be appropriate. From Eq. (1) we get $\mathrm{d} r=\frac{\partial \alpha}{\partial T} \mathrm{~d} T+\frac{\partial \phi}{\partial \alpha} \mathrm{d} \alpha$,

The operator Eq. (2) in amputated form is written down

$d=\mathrm{d} T \frac{\partial}{\partial T}+\mathrm{d} \alpha \frac{\partial}{\partial \alpha}$,

or in form

$\xi=a \frac{\partial}{\partial T}+b \frac{\partial}{\partial \alpha}$.

The quantities $a, b$ (masses) are components of $\xi$ in the coordinate system $(T, \alpha)$. The differential operator $\xi$ is called the vector field. It has a clear geometric interpretation. We see it as tiny arrows arranged in the plane $(T, \alpha)$. The $\xi$ operator consists of two parts. One proportional to, directed along the line of constant $\alpha$ value, and the second, proportional to $\frac{\partial}{\partial \alpha}$, directed along the line of constant $T$ value. It is noteworthy that $a \frac{\partial}{\partial T}$ and $b \frac{\partial}{\partial \alpha}$ alone can be treated as vector fields. The quantity $\xi(r)$ is the gradient (scalar field), and includes information on how the process rate changes in all directions on the plane $(T, \alpha)$. Each stage of the process should be treated as an independent transition. It begins to proceed at a certain temperature $T_{\alpha=0}$. Since then, the rate of this change increases from zero to the maximum, which is achieved at $\left(T_{\mathrm{m}}, \alpha_{\mathrm{m}}\right)$, and then decreases to zero at $\alpha \rightarrow 1$. The size and direction of the arrows of $\xi$ operator in the plane $(T, \alpha)$ should reflect the course of the change.

After the separation of variables Eq. (1) takes form

$r=\frac{\mathrm{d} \alpha}{\mathrm{d} t}=k(T) f(\alpha)$

This is the traditional form of kinetic equation. The function $k(T)$ is described by Arrhenius equation

$k(T)=A \exp \left(-\frac{E}{R T}\right)$.

Now Eq. (2) can be written down as follows

$\mathrm{d} r=f(\alpha) \frac{\partial k(T)}{\mathrm{d} T} \mathrm{~d} T+k(T) \frac{(\partial f(\alpha))}{\partial \alpha} \mathrm{d} \alpha$

Derivative $\frac{\partial f(\alpha)}{\partial \alpha}$ changes sign after maximum of $f(\alpha)$ function, dependent only on the form of this function (kinetic model). The process rate instead reaches maximum for $\mathrm{d} r=0$, at $\left(T_{\mathrm{m}}, \alpha_{\mathrm{m}}\right)$, corresponding to this point. Maximum of process rate is shifted with respect to the maximum of $f(\alpha)$ function into the higher temperature range. The $\alpha_{\mathrm{m}}$ value can depend on sample heating rate. There should be added that from the condition $\mathrm{d} r=0$, after transformations of Eq. (7) Kissinger equation is obtained.

It follows from the presented description that the course of each stage of the process (each independent 
transformation) is defined by three values: Arrhenius parameters $A$ and $E$ and the form of the function $f(\alpha)$ (kinetic models).

For different transitions these parameters are different. As a result, they proceed in different temperature ranges. The change of kinetic parameters usually requires application of extreme measures (such as catalysts). We are interested in conducting non-catalytic processes, during thermogravimetric measurements, under non-isothermal conditions at a constant sample heating rate $\frac{\mathrm{d} T}{\mathrm{~d}_{t}}=\beta=$ const, in a given series of measurements.

It is assumed that in such a case, Eq. (5) can be written as $[1,10-13]$

$\frac{\mathrm{d} \alpha}{\mathrm{d} T}=\frac{k(T) f(\alpha)}{\beta}$.

This notation indicates that under non-isothermal conditions, at a constant sample heating rate, for each stage of the process, the form of the function $k(T)$, and thus the parameters $A$ and $E$ of the form of the function $f(\alpha)$ should be maintained $[4,14]$. The influence of the sample heating rate $(\beta)$ on the course of transformations should be compensated by temperature range $T_{\alpha=0} ; T_{\alpha=1}$ [4].

The aim of thermogravimetric studies is to determine, for the stages of investigated process, $A$ and $E$ parameters and kinetic models most consistent with experimental data. During the standard thermogravimetric measurements sample temperature, TG, DTG and HF functions, and mass spectra of the formed gaseous products in time are recorded. Solid products are identified by XRD method. On this basis, a division into stages is made and $\alpha(T)$ dependencies are determined for the stages. The methods of analysing the results and kinetic models recommended by ICTAC Kinetics Committee are given in [10]. These are in particular the Kissinger method and the isoconversional method. In our work we do not include the results obtained by isoconversional method. The results of such calculations are given in work [4].

\section{Methods of calculations}

Methods of calculation used for elaboration of the experimental data proposed in this paper starts with the substitution of $\ln A=\theta$ in Eq. (6). As a result we obtain

$k(T)=\exp \left(-\frac{E-\theta R T}{R T}\right)$.

This form reveals the difficulties in determining the parameters $A$ and $E$. Mathematical aspects of these issues are presented in [15]. In general one parameter should be specified. Theoretically, such possibility is provided by
Kissinger method, if appropriate correct values of kinetic parameters are achieved by this method. It is often impossible, for example, when the peaks of the DTG charts are narrow and are located very close to $T_{\mathrm{m}}$ values for the different sample heating rates. During the calculations the Eq. (8) transformed to the form presented below will be used

$g(\alpha)=\frac{A}{\beta} \int_{T_{\alpha=0}}^{T_{\alpha=1}} \exp \left(-\frac{E}{R T}\right) \mathrm{dT}$.

Equation (10) has no analytical solution. It should be added that in order to perform calculations numerically one needs to know temperature ranges $T_{\alpha=0} ; T_{\alpha=1}$ for each heating rate and for each stage. Equation (10) will be used to determine kinetic models [4]. A good approximation (10), easier for use in kinetic calculations, is the CoatsRedfern Eq. [13]

$\ln \left[\frac{g(\alpha)}{T^{2}}\right]=F(T)=\ln \left[\frac{A R}{\beta E}\left(1-\frac{2 R T_{\mathrm{m}}}{E}\right)\right]-\frac{E}{R T}$.

This equation can be therefore used during the building of mathematical models describing the courses of the processes under non-isothermal conditions, at constant sample heating rates. To perform the calculations it is necessary to know the form of $g(\alpha)$ function (kinetic model), Arrhenius parameters $A$ and $E$ and $T_{\mathrm{m}}$. It is proposed to take as $T_{\mathrm{m}}$ the temperature corresponding to the maximum of the DTG function.

We are also interested in the application of Eq. (11) during the elaboration of measurement results. To apply Eq. (11) the values of $\alpha(T)$ function should be determined over a wide temperature range. It is noteworthy that for the most common kinetic models, at $\alpha \rightarrow 0, g(\alpha) \rightarrow 0$ and at $\alpha \rightarrow 1 ; g(\alpha)$ becomes undefined. It should be borne in mind while performing calculations by this method.

\section{Kissinger method}

The basis of Kissinger method are the parameters describing the process rate maxima $\left(T_{\mathrm{m}}, \alpha_{\mathrm{m}}\right)$, determined at different heating rates of the samples [12]. For maximum $\frac{\mathrm{d}^{2} \alpha}{\mathrm{d} t^{2}}=0$. Differentiating Eq. (8) we get after transformations

$\frac{E \beta}{R T_{\mathrm{m}}^{2}}=-A f^{\prime}\left(\alpha_{\mathrm{m}}\right) \exp \left[-\frac{E}{R T_{\mathrm{m}}}\right]$.

Equation (12) requires, that $f^{\prime}\left(\alpha_{\mathrm{m}}\right)<0$.

In this method therefore kinetic models meeting this condition may be used. It should be recalled that, the $f^{\prime}\left(\alpha_{\mathrm{m}}\right)$ occurring in this equation refers to the value of the derivative at the point of maximum reaction rate, and not to the corresponding maxima of the $f(\alpha)$ function. 
Rearranging (12) and adjusting the result to measurements performed at different samples heating rates Kissinger equation is obtained

$\ln \left(\frac{\beta_{\mathrm{i}}}{T_{\mathrm{m}, \mathrm{i}}^{2}}\right)=\ln \left[-\frac{A R}{E} f^{\prime}\left(\alpha_{\mathrm{m}}\right)\right]-\frac{E}{R T_{\mathrm{m}, \mathrm{i}}}$.

If $\alpha_{\mathrm{m}, \mathrm{i}}$ do not depend on sample heating rate, then activation energy $E$ and value of expression $\ln \left[-\frac{A R}{E} f^{\prime}\left(\alpha_{\mathrm{m}}\right)\right]=B$ can be calculated by linear regression method.

Knowing $B A f^{\prime}\left(\alpha_{\mathrm{m}}\right)$ is calculated from the equation

$-A f^{\prime}\left(\alpha_{\mathrm{m}}\right)=\frac{E}{R} \exp (B)$.

To calculate $A$ one needs to know the kinetic model referring to a given stage (the form of $f(\alpha)$ function). The way of determining kinetic model is described in works $[4,10]$.

After determining the form of the $f(\alpha)$ function a derivative $f^{\prime}\left(\alpha_{\mathrm{m}}\right)$ is calculated. Knowing $A f^{\prime}\left(\alpha_{\mathrm{m}}\right)$ and $f^{\prime}\left(\alpha_{\mathrm{m}}\right)$ the Arrhenius factor $A$ is calculated.

\section{Application of Coats-Redfern equation}

In conventional way of kinetic parameters determination from the Coats-Redfern equation statistic methods are used $[10,11,16-19]$. Using this way the good results sometimes are not achieved. In this work the analogue method is applied. This consists in comparison of the courses of $\alpha(T)$ functions determined from the measurements and calculated. The good consistence in the wide range was required. While performing the calculations the courses of $\Delta \alpha$ plots (the differences between the calculated and determined in measurements values) were visualised at the computer display. The plots of $f(\alpha)$ functions, DTG and calculated reaction rates were also compared. The calculations were performed in the following way.

Using the Coats-Redfern Eq. (11) first, changing the $A$ and $E$ values, $F(T)$ function was calculated. Then the $g(\alpha)$ was calculated from the equation

$g(\alpha)=T^{2} \exp [F(T)]$

Equation (15) is appropriate for various kinetic models. The way of conversion degree calculations depends, however, on the form of kinetic model. For example for A2 model

$g(\alpha)=[-\ln (1-\alpha)]^{\frac{1}{2}}$,

hence

$\alpha=1-\exp \left[-g^{2}(\alpha)\right]$.

Knowing $\alpha(T)$ from the equation
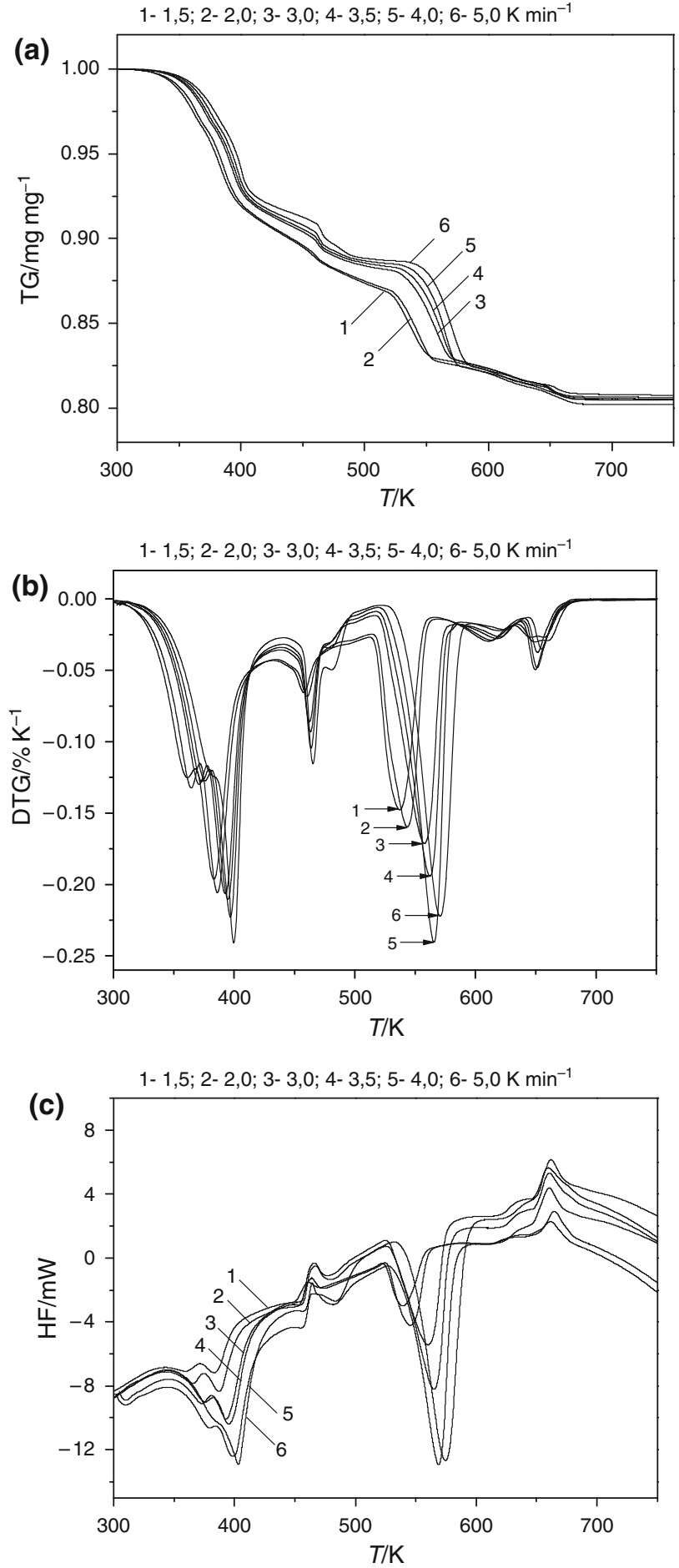

Fig. 1 Dependence of TG, DTG and HF function on temperature. Decomposition of $\left(\mathrm{NH}_{4}\right)_{6} \mathrm{Mo}_{7} \mathrm{O}_{24} \cdot 4 \mathrm{H}_{2} \mathrm{O}$ in argon

$r(T, \alpha)=A \exp \left[-\frac{E}{R T}\right] f(\alpha)$,

the process rates for given stage are calculated for different sample heating rates. 
(a)
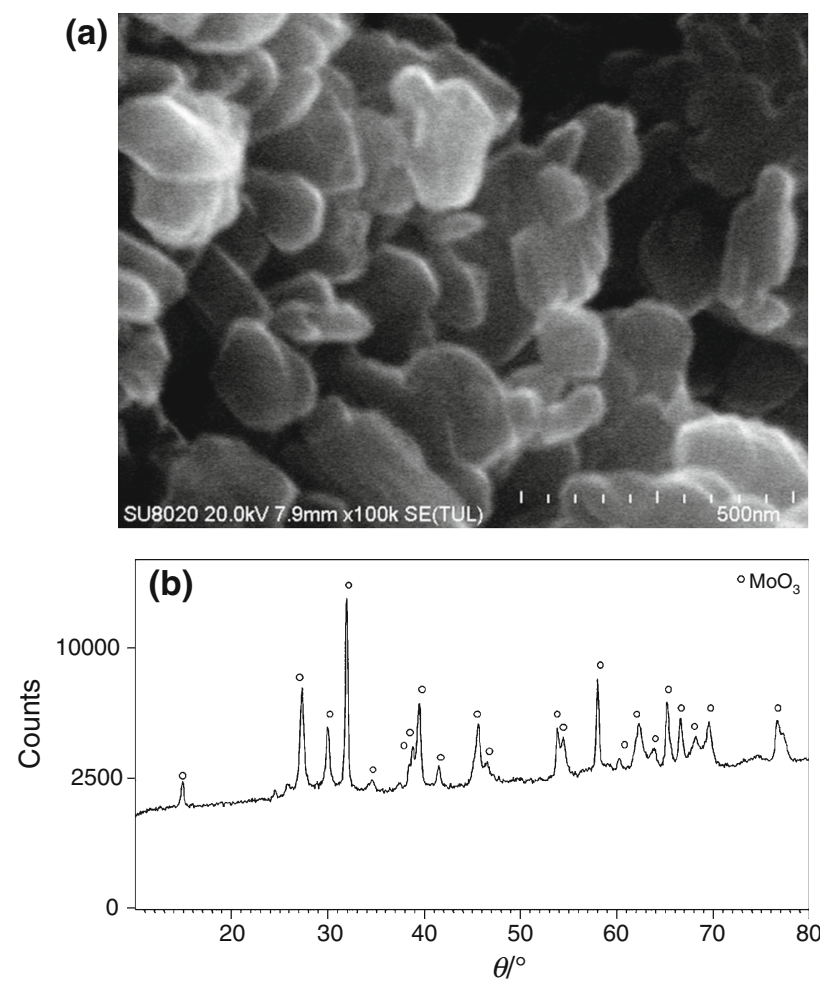

Fig. 2 XRD diffractogram and SEM image of a sample after $\left(\mathrm{NH}_{4}\right)_{6} \mathrm{Mo}_{7} \mathrm{O}_{24} \cdot 4 \mathrm{H}_{2} \mathrm{O}$ decomposition in argon

\section{Experimental}

$\left(\mathrm{NH}_{4}\right)_{6} \mathrm{Mo}_{7} \mathrm{O}_{24} \cdot 4 \mathrm{H}_{2} \mathrm{O}$ from Sigma Aldrich was used. Thermal decomposition of $\left(\mathrm{NH}_{4}\right)_{6} \mathrm{Mo}_{7} \mathrm{O}_{24} \cdot 4 \mathrm{H}_{2} \mathrm{O}$ was carried out in argon (6.0 purity, Messer). Q600 (TA Instruments) TG-DSC apparatus was used. The gaseous products were determined by mass spectrometry method using Pfeifer Vacuum ThermoStar GDS 601 apparatus. The solid products were identified by XRD method. PANalytical B.V. apparatus and computer software X'Pert HighScore 1.0 with incorporated ICDD spectra library were used. Morphology of the samples was investigated by SEM method. HITACHI SU8020 apparatus with cold field emission was used.

\section{Results}

During the TG-DSC measurements the weighted amounts were in the order of $20 \mathrm{mg}$. The sample temperature and TG, DTG and HF functions were registered in time along with the mass spectra of the gaseous products.

\section{Analysis of TG, DTG and HF plots}

It is worth noting that $\left(\mathrm{NH}_{4}\right)_{6} \mathrm{Mo}_{7} \mathrm{O}_{24} \cdot 4 \mathrm{H}_{2} \mathrm{O}$ decomposes quite easily. The process proceeds with formation of

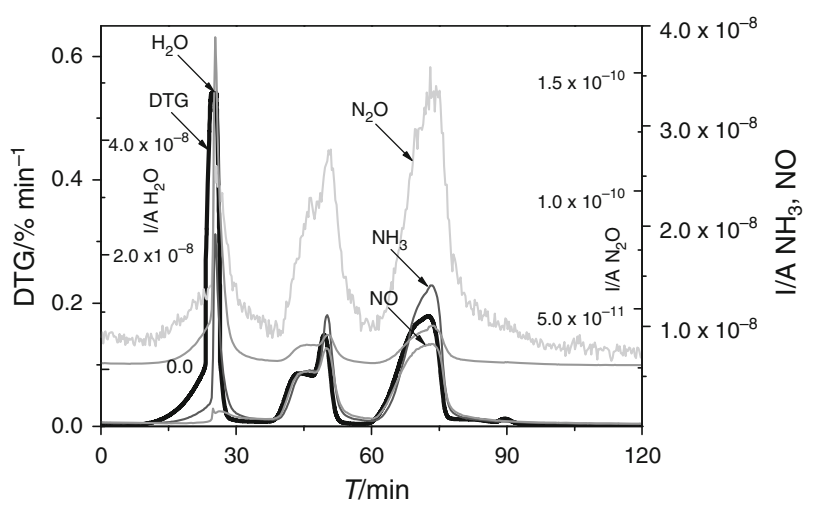

Fig. 3 Plot of DTG and mass spectra of $\mathrm{H}_{2} \mathrm{O}, \mathrm{NH}_{3}, \mathrm{NO}$ and $\mathrm{N}_{2} \mathrm{O}$. Decomposition of $\left(\mathrm{NH}_{4}\right)_{6} \mathrm{Mo}_{7} \mathrm{O}_{24} \cdot 4 \mathrm{H}_{2} \mathrm{O}$ in argon. $\beta=4 \mathrm{~K} \mathrm{~min}^{-1}$

several molecules in elementary act. This creates experimental difficulties during investigation of its course. The analysis of the obtained results is also difficult. In Fig. 1 plots of TG, DTG and HF dependence on temperature are presented. In kinetic calculations, the results concerning TG and DTG, containing about 110 thousands values, were used. These sets were evaluated by neural networks method [19]. As described variables TG or DTG, and as describing variables $T$ and $\beta$ were used. Whole sets were described with high accuracy by one neural model (GRNN network). This means that the determined TG and DTG sets were numerous enough and depended only on $T$ and $\beta$.

Figure 2 presents the XRD diffractogram and SEM image of the sample obtained after completion of $\left(\mathrm{NH}_{4}\right)_{6} \mathrm{Mo}_{7} \mathrm{O}_{24} \cdot 4 \mathrm{H}_{2} \mathrm{O}$ decomposition.

$\mathrm{MoO}_{3}$ (ICDD card 00-005-508) was obtained.

The process proceeded in five stages. Stage I, III and IV are endothermic transitions and II and $\mathrm{V}$ are exothermic transitions. At higher sample heating rates the peaks of DTG and HF plots are shifted into the range of higher temperature. Also the temperature ranges $T_{\alpha \rightarrow 0} ; T_{\alpha \rightarrow 1}$ are then wider for the stages.

In Fig. 3, the plots of mass spectra of $\mathrm{H}_{2} \mathrm{O}(\mathrm{m} / \mathrm{e}=18)$; $\mathrm{NH}_{3}(m / e=17) ; \mathrm{NO}(m / e=30)$ and $\mathrm{N}_{2} \mathrm{O}(m / e=44)$ obtained for sample heating rate equal $4 \mathrm{~K} \mathrm{~min}^{-1}$ are presented as an example. To facilitate the analysis also the DTG is plotted.

There was assumed that $\mathrm{NO}$ and $\mathrm{N}_{2} \mathrm{O}$ were formed during the oxidation of evolved $\mathrm{NH}_{3}$ by the oxygen contained at the trace level in argon. This process should not influence the registered mass change of the samples [20].

In stages I, II and III $\mathrm{H}_{2} \mathrm{O}, \mathrm{NH}_{3}, \mathrm{NO}$ and $\mathrm{N}_{2} \mathrm{O}$ were evolved and the peaks of mass spectra plots concerning $\mathrm{H}_{2} \mathrm{O}$ were shifted into the range of higher temperature with respect to the peaks of DTG plots. In stages IV and V small amounts of $\mathrm{H}_{2} \mathrm{O}$ and $\mathrm{NH}_{3}$ were formed. 
Table 1 List of mass balances for the stages

\begin{tabular}{|c|c|c|c|c|c|c|}
\hline \multirow[t]{2}{*}{$\beta / \mathrm{K} \min ^{-1}$} & \multicolumn{5}{|c|}{ Mass losses in stages/mass\% } & \multirow[t]{2}{*}{$\sum / \operatorname{mass} \%$} \\
\hline & I & II & III & IV & V & \\
\hline 1.5 & 9.586 & 2.332 & 5.366 & 1.170 & 1.036 & 19.491 \\
\hline 2.0 & 9.437 & 2.718 & 5.286 & 1.247 & 1.116 & 19.805 \\
\hline 3.0 & 8.770 & 2.694 & 5.830 & 1.155 & 1.082 & 19.539 \\
\hline 3.5 & 9.108 & 2.373 & 5.718 & 1.113 & 1.165 & 19.477 \\
\hline 4.0 & 8.705 & 2.638 & 5.947 & 1.312 & 0.782 & 19.384 \\
\hline 5.0 & 8.240 & 3.004 & 6.110 & 1.007 & 0.896 & 19.257 \\
\hline
\end{tabular}

Decomposition of $\left(\mathrm{NH}_{4}\right)_{6} \mathrm{Mo}_{7} \mathrm{O}_{24} \cdot 4 \mathrm{H}_{2} \mathrm{O}$ in argon

In stage II less volatile products were formed than in stage I. There was also significantly less $\mathrm{H}_{2} \mathrm{O}$ in comparison with $\mathrm{NH}_{3}$ and NO. In stage III more volatile products evolved than in stage II. In stage IV small amount of volatile products, mainly $\mathrm{H}_{2} \mathrm{O}$, was evolved. In stage $\mathrm{V}$ small amounts of $\mathrm{NH}_{3}$ and $\mathrm{H}_{2} \mathrm{O}$ were formed.

Let's analyse now the reasons why the deflections in plots appear at the beginning of stage I and at the end of stage II. In case of stage I it is important that at the higher sample heating rates plots of DTG and HF were shifted into the range of lower temperature. The investigated process is highly exothermic. At higher process rates, the amount of delivered heat is too small. In result the temperature of the sample gets lower. There should be added that at higher weighted amounts e.g. $40 \mathrm{mg}$, the looping of DTG plots took place. The described effect was treated as a disturbance that should not influence the location of peaks maxima at DTG plots, used for calculations by Kissinger method.

In plots of mass spectra of volatile products formed in stage II, the maxima are located in a similar way as in stage I. After the maxima, the deflections appeared in mass spectra of $\mathrm{NH}_{3}$ and $\mathrm{NO}$. However, at the plots of DTG, at this range of temperature, a small peak appeared. This effect was treated as disturbance, that should not influence the location of DTG plot maxima for this stage.

Mass balance and overall stoichiometric equations for stages

Mass balances of the samples were performed on the basis of TG plots. The temperature ranges were determined taking into account the beginning and the end of DTG plots for given stage. The results are listed in Table 1.

The theoretical mass loss of the sample for the decomposition of $\left(\mathrm{NH}_{4}\right)_{6} \mathrm{Mo}_{7} \mathrm{O}_{24} \cdot 4 \mathrm{H}_{2} \mathrm{O}$ into $\mathrm{MoO}_{3}$ equals 18.49 mass \%. The mass losses determined experimentally are slightly higher. The mass loss of the sample in stage I changed from 9.586 to 8.24 , in stage II from 2.332 to 3.004 , in stage III from 5.286 to 6.11 , in stage IV from 1.312 to 1.007 , and in stage $\mathrm{V}$ from 1.165 to 0 . 896 mass\%.

On the basis of presented results, the following overall stoichiometric equations for the stages have been proposed.

Stage I

$\left(\mathrm{NH}_{4}\right)_{6} \mathrm{Mo}_{7} \mathrm{O}_{24} \rightarrow\left(\mathrm{NH}_{4}\right)_{4} \mathrm{Mo}_{7} \mathrm{O}_{23} \mathrm{H}_{2} \mathrm{O}+2 \mathrm{NH}_{3}+4 \mathrm{H}_{2} \mathrm{O}$.

The theoretical mass loss of the sample in stage I, according to the above equation, equals 8.518 mass $\%$.

\section{Stage II}

$$
\begin{aligned}
\left(\mathrm{NH}_{4}\right)_{4} \mathrm{Mo}_{7} \mathrm{O}_{23} \mathrm{H}_{2} \mathrm{O} \rightarrow & \left(\mathrm{NH}_{4}\right)_{3} \mathrm{Mo}_{7} \mathrm{O}_{22.5} \mathrm{H}_{2} \mathrm{O}+\mathrm{NH}_{3} \\
& +0.5 \mathrm{H}_{2} \mathrm{O} .
\end{aligned}
$$

The theoretical mass loss of the sample in stage II, according to the above equation, equals 2.104 mass\%.

\section{Stage III}

$$
\begin{aligned}
\left(\mathrm{NH}_{4}\right)_{3} \mathrm{Mo}_{7} \mathrm{O}_{22.5} \mathrm{H}_{2} \mathrm{O} \rightarrow & \left(\mathrm{NH}_{4}\right) \mathrm{Mo}_{7} \mathrm{O}_{21.5}+2 \mathrm{NH}_{3} \\
& +2 \mathrm{H}_{2} \mathrm{O} .
\end{aligned}
$$

The theoretical mass loss of the sample in stage III, according to this equation, equals 5.66 mass\%.

The experimental results did not allow proposing separate stoichiometric equations for stages IV and V. The following overall equation have been proposed

\section{Stage IV and stage $V$}

$\left(\mathrm{NH}_{4}\right) \mathrm{Mo}_{7} \mathrm{O}_{21.5} \rightarrow 7 \mathrm{MoO}_{3}+\mathrm{NH}_{3}+0.5 \mathrm{H}_{2} \mathrm{O}$.

In this case the overall, theoretical sample mass loss in stages IV and V equals 2.104 mass\%. There should be added that during the calculation of conversion degrees the sample mass losses determined experimentally were used, not the values calculated from the proposed stoichiometric equations. The solid products formed in stages I and II were obtained running isothermal transitions. The product formed in stage I was obtained by heating the sample in argon at $411 \mathrm{~K}$ for $1 \mathrm{~h}$, and the product formed in stage III was obtained by heating the sample in argon at $601 \mathrm{~K}$ for $1 \mathrm{~h}[2,5]$.

No patterns corresponding to postulated intermediate products were found in ICDD spectra library. 

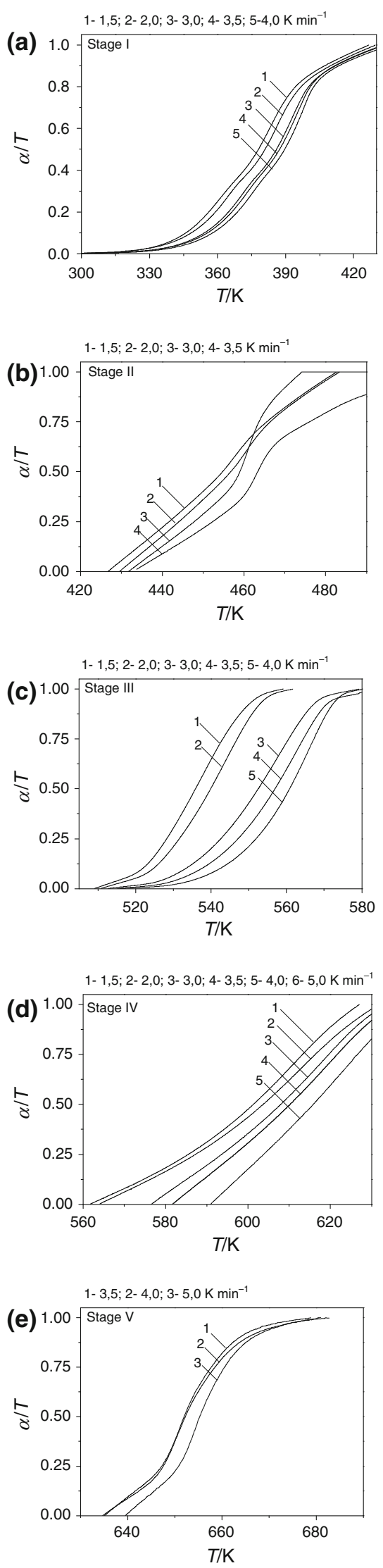

Fig. 4 Dependencies of $\alpha(T)$ for the stages. Decomposition of $\left(\mathrm{NH}_{4}\right)_{6} \mathrm{Mo}_{7} \mathrm{O}_{24} \cdot 4 \mathrm{H}_{2} \mathrm{O}$ in argon

Analysis of $\alpha(T)$ plots for distinguished stages

The conversion degree for a stage was calculated from equation

$\alpha=\frac{m_{0}-m}{\Delta m}$.

In Fig. 4, dependencies of conversion degrees on temperature and sample heating rates obtained for the stages are presented.

The $\alpha(T)$ set for single heating rate contained about 1,000 values. These sets were also evaluated by neural networks method. The described variable in this case were $\alpha(T)$ functions, and the describing variables were $T$ and $\beta$.

Each $\alpha(T)$ set, concerning given stage, was also described by neural model (MLP or GRNN networks).

In Kissinger method, the courses of $\alpha(T)$ are used for determining the kinetic model (form of $f(\alpha)$ function), and in the Coats-Redfern method for determining all the kinetic parameters. The plots of $\alpha(T)$ for stage I at higher sample heating rates are shifted into the higher temperature range. In this case, all the results can be used for the calculations. The previously discussed disturbance causes the waving of $\alpha(T)$ plots in the middle part. This may affect the accuracy of the calculations.

In case of stage II, at higher sample heating rates, due to the disturbances plots of $\alpha(T)$ are not monotonic. Such results cannot be used in further calculations. In case of stage III and IV plots of $\alpha(T)$ are monotonic. At higher sample heating rates, the plots are also shifted into a higher temperature range. These results can be used in further calculations. In case of stage $\mathrm{V}$ the determined dependences of $\alpha(T)$ could be determined only for the higher sample heating rates.

Analysis of the results

\section{Kissinger method}

The data for calculations by Kissinger method are listed in Table 2. They are determined for different sample heating rates. The temperature $T_{\mathrm{m}}$ has been determined on the basis of DTG plots. Knowing $T_{\mathrm{m}}$, the values of $\alpha_{\mathrm{m}}(T)$ were read out for the stages from the $\alpha(T)$ data set shown in Fig. 4 . For example, for stage II and III, the temperature ranges are given. For higher sample heating rates the temperature ranges are larger.

Figure 5 presents the plots of $\ln \left(\frac{\beta_{\mathrm{i}}}{T_{\mathrm{mi}}^{2}}\right) \div \frac{1,000}{T_{\mathrm{mi}}}$ obtained for the stages on the basis of data from Table 2 . 
Table 2 List of the results for calculations by Kissinger method

\begin{tabular}{|c|c|c|c|c|c|c|c|c|c|c|c|c|}
\hline \multirow[t]{2}{*}{$\overline{\beta / \mathrm{K} \min ^{-1}}$} & \multicolumn{2}{|c|}{ Stage I endo } & \multicolumn{3}{|c|}{ Stage II egzo } & \multicolumn{3}{|c|}{ Stage III endo } & \multicolumn{2}{|c|}{ Stage IV endo } & \multicolumn{2}{|c|}{ Stage V egzo } \\
\hline & $T_{\mathrm{m}} / \mathrm{K}$ & $\alpha_{\mathrm{m}}$ & $T_{\mathrm{m}} / \mathrm{K}$ & $\alpha_{\mathrm{m}}$ & $\Delta T / \mathrm{K}$ & $T_{\mathrm{m}} / \mathrm{K}$ & $\alpha_{\mathrm{m}}$ & $\Delta T / \mathrm{K}$ & $T_{\mathrm{m}} / \mathrm{K}$ & $\alpha_{\mathrm{m}}$ & $T_{\mathrm{m}} / \mathrm{K}$ & $\alpha_{\mathrm{m}}$ \\
\hline 1.5 & 383.34 & 0.609 & 457.92 & 0.581 & $426.7-457.9$ & 537.95 & 0.574 & $509-559.1$ & 610.61 & 0.693 & - & - \\
\hline 2.0 & 386.10 & 0.609 & 460.58 & 0.604 & 429.5 & 544.22 & 0.654 & $511-561.7$ & 612.24 & 0.667 & - & - \\
\hline 3.0 & 392.32 & 0.938 & 462.35 & 0.619 & $433.4-479$ & 557.89 & 0.665 & $512-579.3$ & 618.24 & 0.720 & 649.85 & 0.418 \\
\hline 3.5 & 394.96 & 0.669 & 463.12 & 0.491 & & 562.25 & 0.674 & -582.2 & 620.71 & 0.725 & 651.42 & 0.456 \\
\hline 4.0 & 396.25 & 0.667 & 463.81 & 0.681 & $436.3-472.2$ & 565.75 & 0.689 & $575-580.5$ & 620.85 & 0.731 & 651.67 & 0.477 \\
\hline 5.0 & 399.48 & 0.681 & 465.72 & 0.665 & 436.7 & 571.11 & 0.645 & $517-590$ & 624.24 & 0.695 & 655.3 & 0.502 \\
\hline
\end{tabular}

Thermal decomposition of $\left(\mathrm{NH}_{4}\right)_{6} \mathrm{Mo}_{7} \mathrm{O}_{24} \cdot 4 \mathrm{H}_{2} \mathrm{O}$ in argon

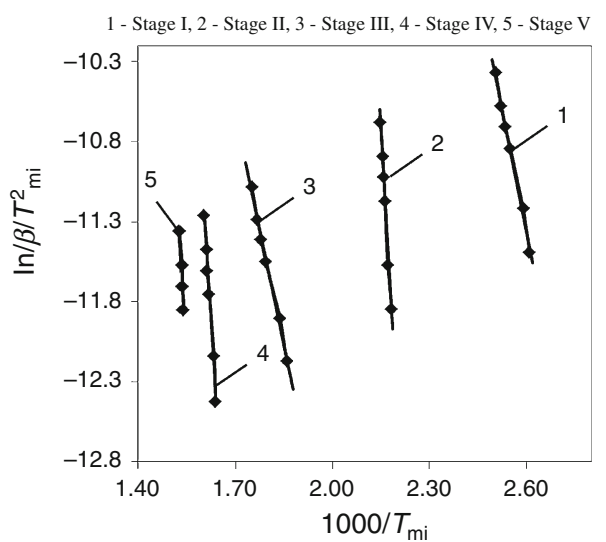

Fig. 5 Plots of $\ln \left(\frac{\beta_{\mathrm{i}}}{T_{\mathrm{mi}}^{2}}\right) \div \frac{1,000}{T_{\mathrm{mi}}}$ for the stages. Thermal decomposition of $\left(\mathrm{NH}_{4}\right)_{6} \mathrm{Mo}_{7} \mathrm{O}_{24} \cdot 4 \mathrm{H}_{2} \mathrm{O}$ in $\operatorname{argon}$

The parameters of Kissinger equation were calculated by linear regression method. Computer software Statistica 6.0 was used. The results are listed in Table 3.

Then kinetic models were determined. For stages I, II i IV model A2 (free nucleation, Avrami Eq. 1) was the most consistent with experimental data

$$
\begin{aligned}
& g(\alpha)=[-\ln (1-\alpha)]^{\frac{1}{2}}, \\
& f(\alpha)=2(1-\alpha)[-\ln (1-\alpha)]^{\frac{1}{2}},
\end{aligned}
$$

$$
f^{\prime}(\alpha)=-2[-\ln (1-\alpha)]^{\frac{1}{2}}+\frac{1}{[-\ln (1-\alpha)]^{\frac{1}{2}}} .
$$

The condition $f^{\prime}\left(\alpha_{\mathrm{m}}\right)<0$ is obtained in this case for $\left[-\ln \left(1-\alpha_{m}\right)\right]>0.5$ (i.e. for $\alpha_{m}>0.4$ ). However for the stage III, V model A4 (free nucleation, Avrami Eq. 3) was the most consistent with experimental data

$$
\begin{aligned}
& g(\alpha)=[-\ln (1-\alpha)]^{\frac{1}{4}}, \\
& f(\alpha)=4(1-\alpha)[-\ln (1-\alpha)]^{\frac{1}{4}}, \\
& f^{\prime}(\alpha)=-4[-\ln (1-\alpha)]^{\frac{3}{4}}+\frac{3}{[-\ln (1-\alpha)]^{\frac{3}{4}}} .
\end{aligned}
$$

For this model the condition $f^{\prime}\left(\alpha_{\mathrm{m}}\right)<0$ is obtained at $\left[-\ln \left(1-\alpha_{m}\right)\right]>0.75$ (i.e. for $\alpha_{m}>0.53$ ). For stage $V$ no $\alpha_{\mathrm{m}}$ values fulfilling this condition was obtained.

This example shows that sometimes determination of $\alpha_{\mathrm{m}}$ value from the experimental data can be difficult. The calculated values of $f^{\prime}\left(\alpha_{\mathrm{m}}\right)$ are given in Table 2. The kinetic parameters $f(\alpha), g(\alpha), A$ and $E$ determined by Kissinger method should be physico-chemical values which can be used in calculations by various methods, including the Coats-Redfern method.

\section{Application of Coats-Redfern equation}

First using the kinetic parameters determined by Kissinger method, values of $\alpha_{\mathrm{m}}$ were calculated from the Coats-

Table 3 List of the results calculated by Kissinger method

\begin{tabular}{lcclllll}
\hline Stages & $E / \mathrm{kJ} \mathrm{mol}^{-1}$ & $B^{*}$ & $-A f\left(\alpha_{\mathrm{m}}\right) / 1 \mathrm{~min}^{-1}$ & $R^{2}$ & Models & $-f^{\prime}\left(\alpha_{\mathrm{m}}\right)$ & $A / 1 \mathrm{~min}^{-1}$ \\
\hline I & 84.05 & 14.915 & $3.031 \mathrm{E} 10$ & 0.994 & A2 & 1.0568 \\
II & 290.90 & 64.502 & $2.215 \mathrm{E} 16$ & 0.982 & A2 & 0.7485 \\
III & 79.52 & 5.623 & $4.773 \mathrm{E} 4$ & 0.994 & A4 & 1.0732 \\
IV & 253.18 & 37.666 & 6.81 & 0.990 & A2 & 1.305 & $2.4567 \mathrm{E} 6$ \\
V & 310.20 & 45.604 & - & 0.927 & A4 & - & $3.0226 \mathrm{E} 20$ \\
\end{tabular}

Thermal decomposition of $\left(\mathrm{NH}_{4}\right)_{6} \mathrm{Mo}_{7} \mathrm{O}_{24} \cdot 4 \mathrm{H}_{2} \mathrm{O}$ in argon 

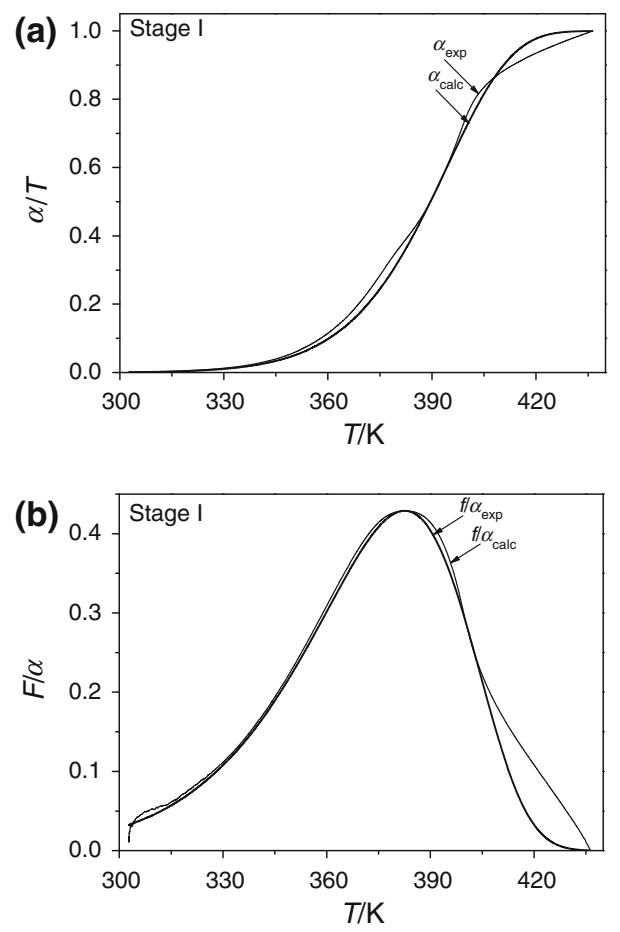

Fig. 6 Comparison of plots of $\alpha(T)$ and $f(\alpha)$. Thermal decomposition of $\left(\mathrm{NH}_{4}\right)_{6} \mathrm{Mo}_{7} \mathrm{O}_{24} \cdot 4 \mathrm{H}_{2} \mathrm{O}$ in argon, stage I, $\beta=4 \mathrm{~K} \mathrm{~min}^{-1}$

Redfern equation. Good consistency was obtained for all the stages and various sample heating rates. For the whole ranges of $\alpha(T)$ in the series, the correct results could not be obtained in this way. For the whole ranges of $\alpha(T)$ the values of $A$ and $E$ coefficients were determined from the Coats-Redfern equation. The analogue method was used. It involves matching the whole calculated curve of $\alpha(T)$ to the curve determined on the basis of measurements. The slope of this curve was corrected by changing the value of the coefficient $E$, while changing the coefficient $A$ the curve was shifted into the appropriate temperature range. The accuracy of the calculations was observed on a computer screen watching the courses of $\Delta \alpha$ plot (differences between the $\alpha(T)$ value determined from the measurements and calculated). The $\alpha(T)$ curves were required to be overlapped in the wide range. Using this way of calculations no problems with obtaining good consistency between the calculated and determined from measurements values of $\alpha(T)$ occurred.

It should be added that, in theory, the calculations by this method can be performed by comparing the courses of the $f(\alpha)$ functions obtained on the basis of $\alpha(T)$ values determined from the measurements and the calculated values, and also by comparing the courses of the experimentally determined DTG function curves and calculated reaction rates. The latter criteria can be attempted to apply when for the entire temperature range the $\alpha(T)$ values can be not experimentally determined.

For stages I, III the kinetic parameters were determined using the courses of $\alpha(T)$ and $f(\alpha)$ function as criteria and for stage II and V the experimentally determined courses of the function.

The calculations for the first series of given stage started from determination of $A$ and $E$ coefficients by Kissinger method. After determining the values of $A$ and $E$ for the series, for the next serial constant, values of $A$ were used and the values of $E$ were changed. In Fig. 6 the results obtained for stage $\mathrm{I}$, at sample heating rate equal to $4 \mathrm{~K} \mathrm{~min}^{-1}$ are shown as an example.

The results obtained for all the stages of investigated process and different sample heating rates are given in Table 4 . The values of $A$ and $E$ coefficients determined by Kissinger method are also presented.

For each stage of the investigated process, for different sample heating rates, almost constant values of the coefficients $A$ and $E$ were obtained. This result is important because it shows that in the case of non-catalytic heterogeneous reactions, conventional methods of chemical kinetics can achieve good results. There was also shown that the values of the parameters $A$ and $E$, determined by Kissinger method, sometimes may not be suitable for all the ranges of $\alpha(T)$ values.

Table 4 The results of calculations by Coats-Redfern method for the whole series

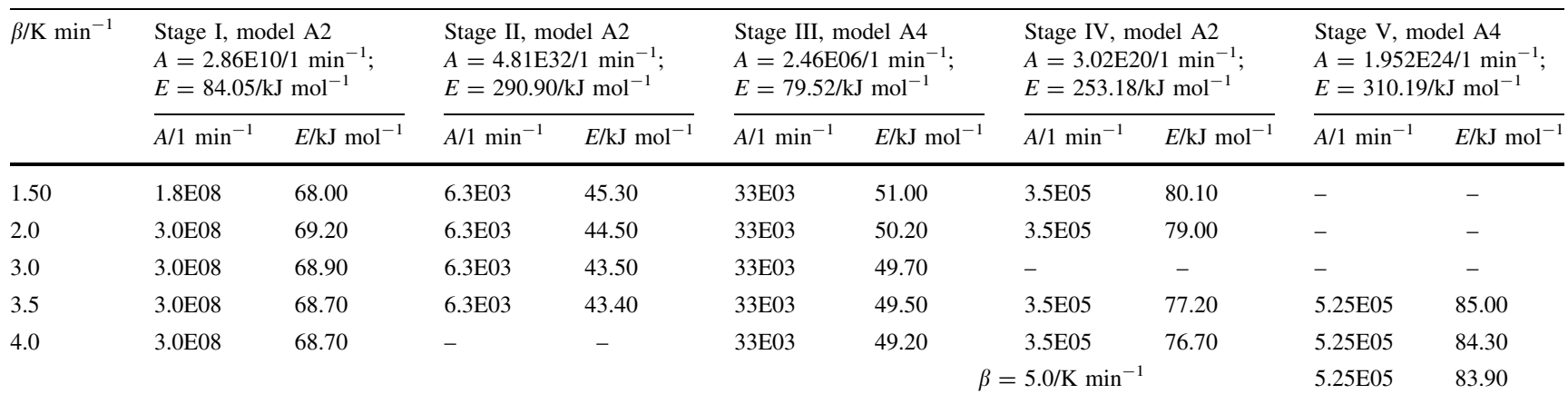



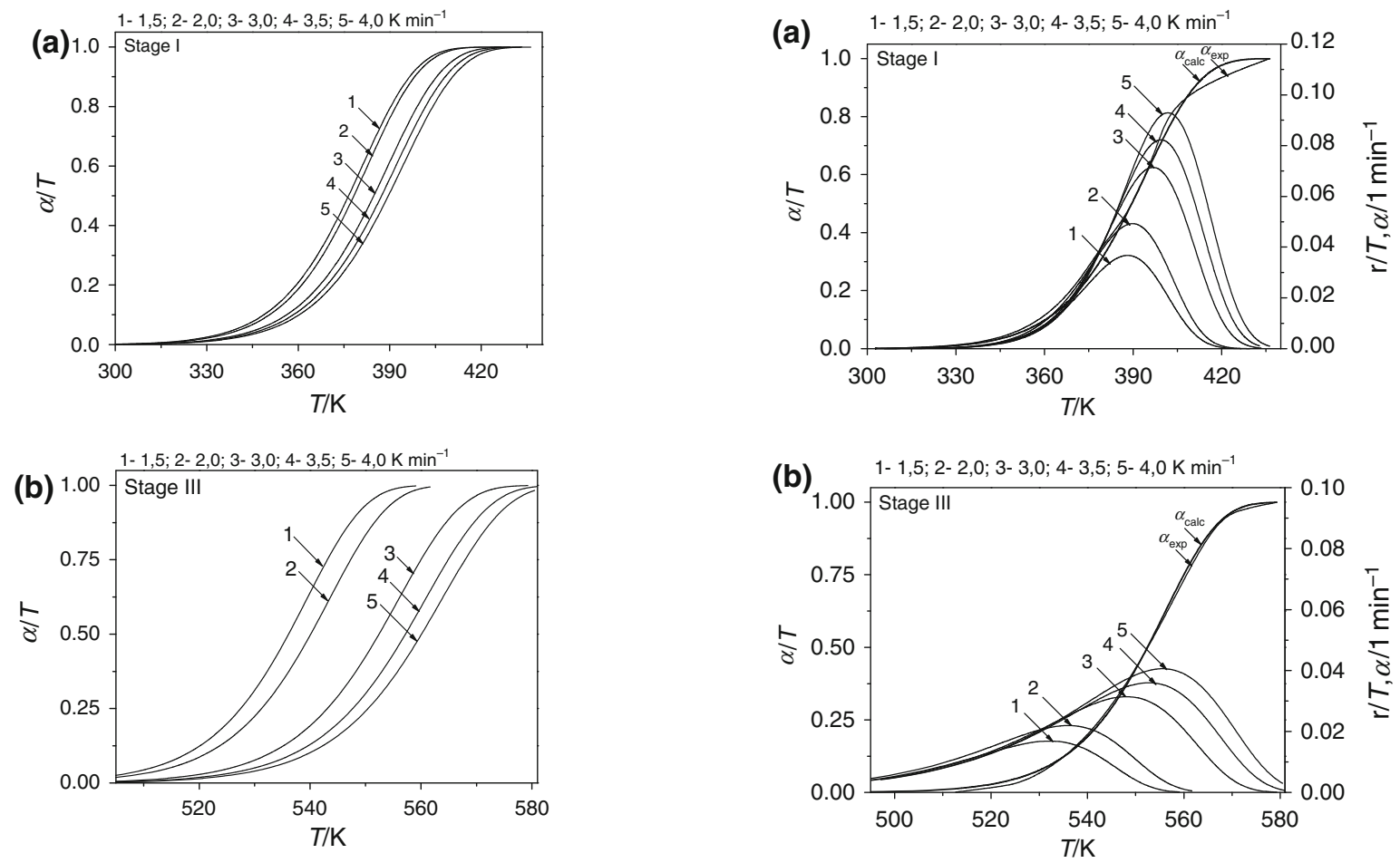

Fig. 7 Plots of calculated $\alpha(T)$ functions for stage I and III. Thermal decomposition of $\left(\mathrm{NH}_{4}\right)_{6} \mathrm{Mo}_{7} \mathrm{O}_{24} \cdot 4 \mathrm{H}_{2} \mathrm{O}$ in argon
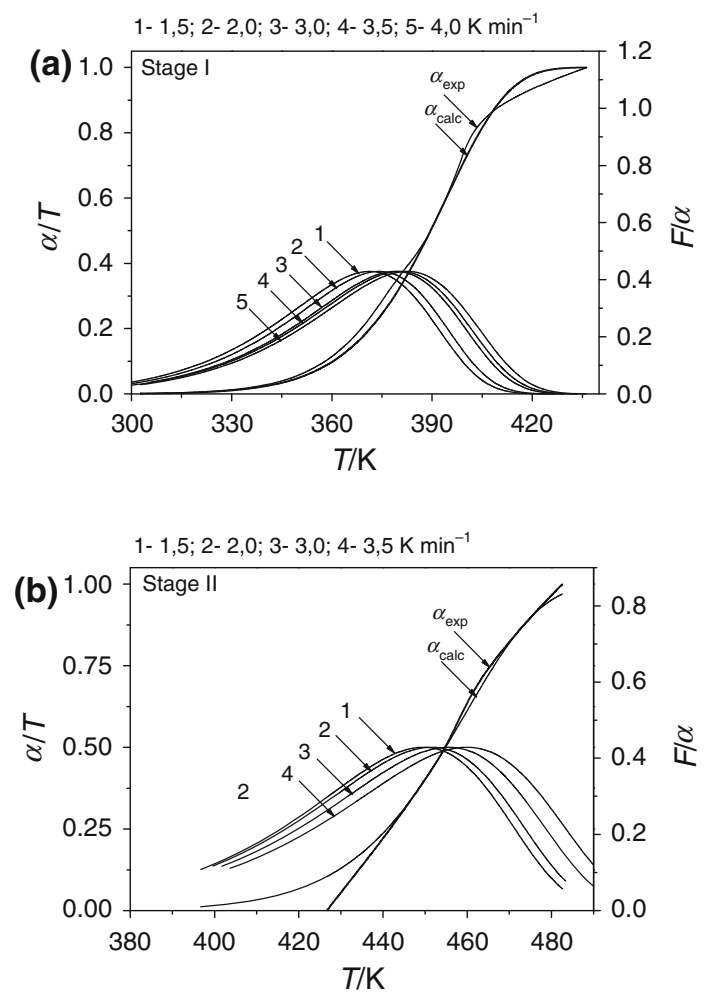

Fig. 8 Plots of $f(\alpha)$ function for stages I and II. Decomposition of $\left(\mathrm{NH}_{4}\right)_{6} \mathrm{Mo}_{7} \mathrm{O}_{24} \cdot 4 \mathrm{H}_{2} \mathrm{O}$ in argon

Fig. 9 Plots of calculated dependencies of process rates in the stages on temperature and sample heating rates. Decomposition of $\left(\mathrm{NH}_{4}\right)_{6} \mathrm{Mo}_{7} \mathrm{O}_{24} \cdot 4 \mathrm{H}_{2} \mathrm{O}$ in argon

The result of kinetic studies should be mathematical models describing the courses of the investigated processes. The obtained results show that in case of investigated process the Coats-Redfern equation along with kinetic parameters given in Table 4 plays such role. For illustration, we give the results of such calculations. In Fig. 7, the dependencies of conversion degrees on temperature and sample heating rate calculated for stage I and III are presented as an example.

At higher sample heating rates $\alpha(T)$ plots are shifted into the higher temperature range. The temperature ranges for the stages are also well consistent with the experimentally determined ranges. The plots of $f(\alpha)$ function are also important. In Fig. 8, the calculated courses of $f(\alpha)$ function for stage I and II are presented as an example. To facilitate the analysis, also the plots of $\alpha(T)$ function calculated and determined from measurements are presented for sample heating rate $\beta=4 \mathrm{~K} \mathrm{~min}^{-1}$ in case of stage $\mathrm{I}$ and $\beta=1.5 \mathrm{~K} \mathrm{~min}^{-1}$ in case of stage II.

Maxima of $f(\alpha)$ function, for given stage, are shifted into the range of lower temperature in comparison with DTG plots. The function $f(\alpha)$ also takes the constant value in these points for different sample heating rates.

The process rate is very important in kinetic investigations. In Fig. 9 the dependencies of process rates on temperature and sample heating rates calculated for stages I 
and III are presented. The plots of $\alpha(T)$ calculated and determined from measurements for $\beta=4 \mathrm{~K} \mathrm{~min}^{-1}$ (stage I) and $\beta=3 \mathrm{~K} \mathrm{~min}^{-1}$ (stage III) calculated and determined from measurements are also presented.

For investigated cases, the process rate increases from zero for $T_{\alpha=0}$, reaches maximal value at temperature $T_{\mathrm{m}}$, and then decreases to zero at $T_{\alpha \rightarrow 1}$. The temperature ranges for the stages and $T_{\mathrm{m}}$ values determined on the basis of these plots are well consistent with the values determined on the basis of DTG function plots.

\section{Conclusions}

The results of the studies on thermal decomposition of $\left(\mathrm{NH}_{4}\right)_{6} \mathrm{Mo}_{7} \mathrm{O}_{24} \cdot 4 \mathrm{H}_{2} \mathrm{O}$ in argon by methods of thermal analysis are presented. The measurements were carried out at sample heating rates $1.5,2,3,3.5,4$ and $5 \mathrm{~K} \mathrm{~min}^{-1}$. The sample mass was in the order of $20 \mathrm{mg}$. The sample temperature, TG, DTG and HF functions and mass spectra of evolved gaseous products were recorded in time. The solid products were identified by XRD method. The gaseous products were determined by mass spectrometry method. The process proceeded in five stages, wherein the steps I, III and IV were endothermic and stage II and V were exothermic changes. After completion of the process $\mathrm{MoO}_{3}$ was obtained. During the transition in stages $\mathrm{H}_{2} \mathrm{O}, \mathrm{NH}_{3}$, $\mathrm{NO}$ and $\mathrm{N}_{2} \mathrm{O}$ were formed. $\mathrm{No} \mathrm{NO}_{2}$ was formed. It was assumed that $\mathrm{NO}$ and $\mathrm{N}_{2} \mathrm{O}$ were formed in reaction of $\mathrm{NH}_{3}$ oxidation by oxygen contained in argon at the trace level.

On the basis of mass balances, stoichiometric equations were proposed for the stages. For distinguished stages $T_{\mathrm{m}}$ and $\alpha_{\mathrm{m}}$ corresponding to the maximal transition rates, temperature ranges $T_{\alpha=0} \div T_{\alpha=1}$ and $\alpha(T)$ were determined. The kinetic parameters $g(\alpha)$ and $f(\alpha)$ (kinetic models) and Arrhenius equation coefficients $A$ and $E$ were determined. For stages I, II and IV the most consistent with experimental data was model A2 (free nucleation, Avrami equation 1), and for stage II and V model A4 (free nucleation, Avrami Eq. 3).

Using the values of coefficients $A$ and $E$ determined by Kissinger method the correct results were not obtained for all the ranges of $\alpha(T)$. The kinetic parameters for whole ranges of $\alpha(T)$ were determined using Coats-Redfern equation. The calculations were performed by analogue method. The courses of $\alpha(T)$ calculated and determined from the measurements were required to be consistent in a wide range. As additional criteria, consistency of $f(\alpha)$ function plots, consistency of DTG function courses and process rates plots were used. Constant values of $A$ and $E$ coefficients were obtained for the stages at the used sample heating rates. The result of kinetic studies should be a mathematical model. It was demonstrated that in case of investigated process, the Coats-Redfern equation plays this role.

Acknowledgements The research was funded by The National Centre for Research and Development in the frame of the realisation of the development Project No. 15-0067-10/2010-2013 and the Dean's Grant "Young Staff” No. 517-06-010-3368/17.

Open Access This article is distributed under the terms of the Creative Commons Attribution License which permits any use, distribution, and reproduction in any medium, provided the original author(s) and the source are credited.

\section{References}

1. Biedunkiewicz A. Aspects of manufacturing of ceramic nanomaterials of $\mathrm{TiC} / \mathrm{C}, \mathrm{TiC}, \mathrm{TiC}-\mathrm{SiC}-\mathrm{C}$ and $\mathrm{Ti}(\mathrm{C}, \mathrm{N})-\mathrm{Si}(\mathrm{C}, \mathrm{N})-\mathrm{Si}_{3} \mathrm{~N}_{4}$ type by the sol-gel method. Szczecin: West Pomeranian University of Technology; 2009 (in Polish).

2. Krawczyk M. Nanometric carbides in the Ti-Mo-Si system obtained by sol-gel method. Szczecin: Doctoral dissertation, West Pomeranian University of Technology; 2013 (in Polish).

3. Biedunkiewicz A, Figiel P, Krawczyk M, Gabriel-Polrolniczak U. Simultaneous synthesis of molybdenum carbides and titanium carbides by sol-gel method. J Therm Anal Cal. 2013; 113(1):253-8.

4. Biedunkiewicz A. Methodology of thermal research in materials engineering. In: Czerwinski F, editor. Heat treatment-conventional and novel applications, Croatia. Rijeka: InTech; 2012. pp. $135-176$.

5. Biedunkiewicz A, Krawczyk M, Gabriel-Polrolniczak U, Figiel P. Analysis of $\left(\mathrm{NH}_{4}\right)_{6} \mathrm{Mo}_{7} \mathrm{O}_{24} \cdot 4 \mathrm{H}_{2} \mathrm{O}$ thermal decomposition in argon. 4th Joint Czech-Hungarian-Polish-Slovak thermoanalytical conference, 24-27 June 2013, Pardubice (Czech Republic), Book of Contributions, pp. 147-150.

6. Peng LM, Wang JH, Li J, He LH, Zhao JH. Synthesis and mechanical properties of ternary molybdenum carbosilicide and its composite. J Mater Lett. 2005;40:2705-7.

7. Jin Y, Liu Y, Wang Y, Ye J. Influence factors and microstructure evolution during preparation of nanocrystalline (Ti, W, Mo, $\mathrm{V})(\mathrm{C}, \mathrm{N})-\mathrm{Ni}$ composite powders. Int J Refract Met Hard Mater. 2009;27(6):957-61.

8. Burnham AK, Weese RK, Wernhoff AP, Maienschein JL. A historical and current perspective on predicting thermal cookoff behavior. J Therm Anal Calorim. 2007;89:407-15.

9. Pernose R. Surfaces. In: The road to reality. London: Jonathan Cape; 2004. pp. 179-193.

10. Vyazovkin S, Burnham AK, Criado JM, Perez-Maqueda LA, Popescu C, Sbirrazzuoli N. ICTAC Kinetics Committee recommendations for performing kinetic computations on thermal analysis data. Thermochim Acta. 2011;520:1-19.

11. Strzelczak A. Analysis of oxidation processes of selected ceramic nanocomposites in dry air. Unpublished doctoral dissertation, Szczecin University of Technology, Poland; 2008 (in Polish).

12. Kissinger HE. Reaction kinetics in differential thermal analysis. Anal Chem. 1957;29:1702-5.

13. Coats AW, Redfern JP. Kinetic parameters from thermogravimetric data. Nature. 1964;201:68-9.

14. Galway AK. What is meant by the term "variable activation energy" when applied in the kinetic analyses of solid state decompositions (crystolysis reaction)? Thermochim Acta. 2003;397:249-68. 
15. Pernose R. Geometry of logarithms, powers, and roots. In: The road to reality. London: Jonathan Cape; 2004. pp. 86-100.

16. Brunaer N, Shacham M. Statistical analysis of linear and nonlinear correlation of the Arrhenius equation constants. Chem Eng Process. 1997;36(3):243-9.

17. Schwaab M, Pinto JC. Optimum reference temperature for reparameterizations of the Arrhenius equation, Part I: problems involving one kinetic constant. Chem Eng Sci. 2007;62(10):2750-64.

18. Biedunkiewicz A, Strzelczak A, Możdżeń G, Lelątko J. Nonisothermal oxidation of ceramic nanocomposites using the example of $\mathrm{Ti}-\mathrm{Si}-\mathrm{C}-\mathrm{N}$ powder: kinetic analysis method. Acta Mater. 2008;56:3132-45.
19. Straszko J, Biedunkiewicz A, Strzelczak A. Application of artificial neural networks in oxidation kinetic analysis of nanocomposites. Pol J Chem Technol. 2008;10:21-7.

20. Biedunkiewicz A, Gabriel U, Figiel P, Sabara M. Investigations on $\mathrm{NH}_{4} \mathrm{VO}_{3}$ thermal decomposition in dry air. $\mathrm{J}$ Therm Anal Calorim. 2012;108:965-70. 